\title{
SIANHOITOA KÄSITTELEVÄ KIRJOITUSJÄLKI
}

\begin{abstract}
ESSKELINEN, MARKKU \& LEHTOLA, JYRKI:

Jälkisanat/Sianhoito-opas. WSOY. Porvoo-Helsinki-Juva 1987.
\end{abstract}

Epäilemättä pahinta mitä nuorten vihaisten miesten ensimmäiselle kirjalle voi tapahtua on kiittävä arvostelu. Tämä kuitenkin on sellainen. Pahoittelen.

\section{Kenttäkamppailun logiikka}

Eino Leinon seuran kokouksessa kuohui, kun Markku Eskelinen suoritti uuden jäsenen kisällinnäytteensä haukkumalla vanhat jäsenet. Monet kokivat, että tässä jo ylitettiin kunnianarvoisan rituaalin rajat. Vanhoilla jäsenillähän rituaalissa hauskaa piti olla eikä uusilla!

Hieman argumentatiivisemmin kirjallisuusanalyysin perinteinen kenttä reagoi Pekka Tammen arvostellessa Jälkisanat/Sianhoito-oppaan (jälj. J/S) Helsingin Sanomiin. Hän väitti, ettei kirjassa tehdä kunnollisia analyyseja suomalaisesta kirjallisuudesta ja sen tutkimuksesta, että se on pelkkää sisällötöntä herjaamista, jolla ei ole mitään hetken julkisuuden yli yltävää arvoa. Hän piti kirjoittajia myös niin lahjattomina kirjallisuustutkijoina, että suositteli heille alan vaihdosta. Sanalla sanoen Tammi oli ottanut kirjan hyvin vakavasti, koska näin painokkaasti (kuuden palstan ykköspaikalle taitetussa arvostelussa) vaati, ettei sitä otettaisi vakavasti. Miksi?

Erilaisia kulttuurianalyysin alueita voidaan - kuten Bourdieu on meille opettanut - tarkastella kenttinä, joiden hierarkiat ovat suhteellisen vakiintuneita. Jos kentälle pyrkii uusia tulokkaita, näiden on tavalla tai toisella kirjoittauduttava entisten kenttäläisten siipien suojaan tai mullistettava ainakin osa kentän perinteisistä rakenteista. Onnistuessaan molemmat strategiat tuottavat tulokkaille aseman (enemmän tai vähemmän uudelleenmuotoutuneen) kentän hierarkiassa.

Eskelinen ja Lehtola pelaavat upporikasta tai rutiköyhää. Heidän kenttästrategiansa on olla kirjoittautumatta kenenkään siipien suojaan ja asettaa kyseenalaiseksi koko suomalainen kirjallisuus ja kirjallisuuskritiikki. He vievät tämän niin pit- källe, että pyrkivät minimoimaan keskustelun vanhan kentän kanssa turhana ajanhukkana väsyneisyydellä, johon vain nuoret miehet voivat olla tarpeeksi vanhoja. Periaatteessa vanha kenttä voi reagoida tällaisiin tulokkaisiin kolmella tavalla. Se voi vaieta tulokkaat kuoliaiksi. Se voi syleillä tulokkaat kuoliaiksi (Esa Saarinen City-lehdessä). Tai se voi käydä taisteluun muuriensa puolustamiseksi. Eino Leinon seuralaisten reaktiot ja Tammen arvostelu ovat puhdas esimerkki viimeisestä vaihtoehdosta. Vanha kenttä puolustautuu kouristuksenomaisesti ja hyväksyy samalla juuri tulokkaiden esittämän asetelman uudeksi kentäksi: vanhat siat vastaan uudet, jotka kyllä tietävät mitä sioille on tehtävä.

Vallassa olevan kirjallisuuden ja kirjallisuuskritiikin kyseenalaistaminen selittää miksi Pekka Tammi suuttui, mutta miksi suuttuja oli juuri Pekka Tammi? Periaatteessa saman kritiikin olisi tarkasti toimitettuun Helsingin Sanomien kulttuuriosastoon voinut kirjoittaa moni muukin asemansa vakiinnuttanut kirjallisuuskriitikko. Tämäkin kuuluu kenttäkamppailun logiikkaan. Pekka Tammi väitteli pikemminkin kemian kuin kirjallisuuskritiikin alueen tutkimukselta näyttävällä strukturalistisen narratologian menetelmiä soveltavalla työllä. Hän on siis vakiintuneella kentällä hankkinut itselleen kentän sisäisen Kriitikon ja Teoreetikon paikan. Uudet tulokkaat vannovat juuri kritiikin ja teorian nimiin ja uhkaavat näin Tammen asemaa kaksinkertaisesti. He eivät vain uhkaa romahduttaa koko sen kentän arvoa, jolla hänellä on asemia vaan uhkaavat lisäksi ottaa hänen asemansa kirjallisuuskritiikin sisäisenä Kriitikkona ja Teoreetikkona. Näin on erityisesti, kun jälkistrukturalismiin nojautuvat tulokkaat helposti voivat tuottaa juuri strukturalismille kohtalokkaita teoreettisia kritiikkejä. Siksi vanhan kentän (epäteoreettisen) kritiikin esittäjäksi valikoitui juuri Tammi ja siksi kritiikki oli niin ehdottoman kompromissitonta ja sokeaa. Tammelle on elintärkeää, että kenttä ei päästä tulokkaita sisäänsä.

Yksi esimerkki. J/S:n credo kir- jallisuuskritiikin alalla on, että kritiikin on keskityttävä tekstuaalisuuteen ja tekstin tuottamisen ehtoihin. Suomalainen kirjallisuus ja kirjallisuuskritiikki (jäljempänä K\&K) ei näin ole tehnyt vaan on eri tavoin ollut sen harhan vallassa, että K\&K voi jollain selkeämmin määrittelemättömäksi jäävällä tavalla parhaimmillaan tavoittaa suoraan sen "todellisen todellisuuden", joka ei ole merkkiprosessien saastuttama vaan ilmenee "välittömästi". Tämä todellisuuden "välitön ilmeneminen" on K\&K:ssa - taaskin parhaimmillaan - luonteeltaan moraalista, mikä merkitsee sitä, että (Tuomas Nevanlinnan vitsin varastaakseni) Eino Leinon seuralaisten mielestä "todellisuudesta kertoo vain kidutettua renkipoikaa käsittelevä kirjallisuus".

$\mathrm{J} / \mathrm{S}$ siis haastaa $\mathrm{K} \& \mathrm{~K}: \mathrm{n}$ tiedonalalle täysin perustavaan keskusteluun tutkimuksen kohteesta. Tässä mielessä on ehkä perusteltua, että tekstin nimenä on Jälkisanat: jos J/S:n kanssa käydään vakavaa keskustelua, on vallassa olevien kantojen todella artikuloitava teoreettisia lähtökohtiaan uudestaan. Tässä mielessä on hämmentävää, että Tammi - joka arvostelussaan sivuttaa täysin tämän kirjan ydinsisällön myös kritisoi J/S:ta kunnollisten kirjallisuuskriittisten tekstianalyysien puutteesta. Ensinnäkin tämä on vale. J/S sisältää tekstianalyysit Veijo Meren Manillaköydestä (suhteutettuna aikaisempiin tulkintoihin), Markku Lahtelan Hallitsijasta, Antti Hyryn Maatuulesta ja Antti Tuurin Pohjanmaasta. Lisäksi useiden muiden kirjailijoiden tuotantoa kommentoidaan. Toiseksi tämä on lukutaidottomuutta. Kirjallisuuskritiikin kannalta $\mathrm{J} / \mathrm{S}$ on teoreettinen pamfletti, joka pyrkii asettamaan kaikkien aiempien tulkintojen taustaolettamukset kyseenalaisiksi. Se on siis ohjelma eikä ohjelman sovellutus. Tekstianalyysit artikuloivat ohjelmaa kukin omalla tavallaan ja tähän tarkoitukseen niiden määrä ja tarkkuus on täysin riittävä.

J/S:n K\&K:n taholta saamasta vastaanotosta päätellen ei siis ole aivan perusteetonta myöskään se, että tekstin nimi on Sianhoito-opas. 


\section{Postmodernin ydin}

J/S ei muistaakseni kertaakaan käytä termiä postmoderni. Silti sekin kuuluu tämän epäkäsitteen alaan asettaessaan kyseenalaiseksi niin tieteen kirjallisuuskritiikin metaforisena samaistumiskohteena kuin merkkiprosesseihin nähden viattoman referentin valta-aseman. Kritiikin kohteena on (V)alistuksen myytti siitä, että tutkimalla järjen avulla kuinka asiat oikein ovat ja asettamalla näin saatu tieto valistumisen ja sivistymisen prosessissa pappisnimitystä vastaan sortuvat kaikki myytit ja päädymme parhaista mahdollisista parhaaseen yhteiskuntaan. Taikausko katoaa.

$\mathrm{J} / \mathrm{S}$ on tietoinen siitä, että poistaessaan merkkien muodostamien tekstien huntuja todellisuuden edestä tieto jatkuvasti törmää uusiin merkeistä teksteiksi rakentuviin huntuihin eikä tästä merkkiprosessista ole ulospääsyä, koska tieto ja tulkinta aina jo rakentuvat merkeistä. Se asettaa ranskalaisittain tehtäväksi jatkuvan pelin ja leikin näillä merkeillä, pelin jossa ainoana sisäisenä logiikkana on pyrkimys jatkuvasti edetä kaikkien merkitystä säätelevien koodien rajalle:

"Dekonstruktion ymmärtäminen tai hyväksyminen tuottaa vaikeuksia vain niille, jotka eivät osaa kirjoittaa ja jotka eivät tajua, että merkityksillä leikkimään kykenevä ihminen on terveempi kuin järjestystä rakastava binäärifilosofi." (J/S s. 103.)

Kuten mm. Roland Barthes jo 1950-luvulla kirjoittamisen nollapisteestä kirjoittaessaan osoitti, on tämä merkitysten leikki loputon, koska jokaisesta koodin murtumisesta syntyy uusi koodi, joka viettelee itselleen murtajaa.

Tämä on siis modernin projektia luonnehtivaa valistusta ivaavaa postmodernia kulttuurikritiikkiä. Hyvä. Otos 2.

Tuija Pulkkinen kuvaa J/S:n kanssa samoihin aikoihin ilmestyneessä esseessään Raja (Tiede \& edistys 4/87) modernia näin:

"Valistukseen ja moderniin kuuluu usko rationaalisuuteen, paljastavaan järkeen. Siihen kuuluu jokaisen tabun murskaaminen, jokaisen myytin purkaminen, jokaisen salaisuuden kertominen, kaiken keinotekoisen riisuminen - ikuinen paljastamisen liike." (Ma 284.)

\section{Postmoderni taas on muuta:}

"Voi ajatella käsityksen rajoista muuttuvan. Ei tarvitse ahdistuneesti paeta rajoja, rikkoa rajoja. Vapauden voi käsittää rajattoman tilan lisäksi rajojen tietoiseksi luomiseksi.

Vapaus tietoisuuden tilana tai itsehallintana, vapaus, jossa rajat ja sääntöjärjestelmä itse tehtyinä ovat positiivisia, ei ole tietenkään uusi ajatus filosofian historiassa. Itämaisista filosofioista se on tuttu; kaikki ZEN-taidot edustavat vapautta, joka saavutetaan hallitsemalla tietyt säännöt, liikkumalla tietyissä rajoissa tietoisena niistä. Hegelin filosofiaan liittyy sama käsitys vapaudesta tietoisuutena rajoista tai subjektin herruutena rajojen suhteen.

Voisi väittää, että postmoderniin kulttuuri-ilmiönä liittyy jotakin samankaltaista - postmoderni ei pyri enää vapauttamaan luonnollista ruumista korsetista vaan tuntee uutta vetoa koristeellisiin epäluonnollisiin aikakausiin. Postmoderni tuntee uutta iloa rajojen luomisesta, se paneutuu kaavojen, muotien ja sääntöjen maailmaan ja nauttii niiden hallinnasta." (Ma. 293)

Tämäkin on modernin projektia luonnehtivaa valistusta ivaavaa postmodernia kulttuurikritiikkiä.

Entäpä jos - herrat Terve deleuze \& Terve guattari-lyotard on oikeassa sanoessaan, että postmoderni oli jo ennen modernia? Että ne siis olennaisesti ovat saman lantin kääntöpuolet.

\section{0-luvun kurjuus}

60-luvun analyysi on J/S:n epäilemättä heikoimpia osuuksia:

", 'Rauhassa', 'rakkaudessa' ja 'tasa-arvossa' ei välttämättä ole muuta vikaa kuin se, että Kallen ja Kaisan lausumina niistä tulee teatteria. Ajatuksia ja tunteita ei koeta, niitä teeskennellään. $\mathrm{Pa}$ teettisuus ja typeryys eivät ole samaa kuin intensiivisyys ja uskottavuus." (J/S s. 165).

Go down, young man. Kirjassa, jonka perusintuitiot jatkuvasti rakentuvat tekstuaaliselle pelille ja leikille, on Aitous heikohko kritiikin lähtökohta. Lahjattomuus on ehkä hiukan parempi, mutta tuskinpa sekään tarjoaa kovin valovoimaisen lähtökohdan juuri 60-luvun erityisyyden analyysille.

Oman näkemykseni mukaan 60 luvun erityispiirre oli kaiken perinteisen vastustaminen. Kyseessä oli nuorison kapina, jossa kaikki perinteiset traditiot haluttiin kyseenalaistaa koskivatpa ne sitten pukeutumista, käyttäytymistä, kunnioitettuja arvoja tai kiellettyjä asioita. Tämän vuoksi 60-lukulaiset pukeutuivat huonosti, käyttäytyivät epäformaalisti, häpäisivät perinteisiä pyhiä ja rikkoivat tabuja. Tämän vuoksi heidän ohjelmalliset positiviteettinsa myöskin saattoivat rakentua vain perinteisesti kiellettyjen asioiden varaan. Näitä olivat viina (huumeet) ja seksi. Näiden kahden keskuksen ympärillä monen 60 lukulaisen merkitysprosessit edelleen nakuttavat. Monet elämänkohtalot osoittavat, että naimista ja ryyppäämistä kiertävät henkilökohtaiset merkitysprosessit eivät pitkäksi aikaa iloisia juhlia tarjoa ja siksi avantgarde nykyisin jo etsiikin merkityksiä muualta.

Oli satunnainen ja Suomea koskeva seikka, että valtiolliset koneistot imivät 60-lukulaisuuden (siltä osin kuin se tänne koskaan tuli) niin nopeasti sisäänsä. Siitä teeskentely ja pateettisuus.

J/S:n 60-lukuanalyysin heikkous ei ole sattuma. J/S:n ohjelma on vallitsevien koodien perusteellisen dekonstruktion ohjelma. Se on 60lukulainen ohjelma. J/S ammentaa Deleuzen ja Guattarin vuonna 1972 ilmestyneestä Anti-Oidipuksesta, jo$\mathrm{ka}$ on 60-luvulla (vaikkakaan ei Suomen 60-luvulla) kirjoitettu kirja. 


\section{Terrorismin vastustamista vastaan}

(Jälki)strukturalistista ja postmodernia kuluttuurianalyysia syytetään usein elitismistä ja epäpoliittisuudesta. Näin kai lähinnä siksi, etteivät sen harjoittajat läheskään aina suostu puhumaan samaa kieltä kuin asemansa talouden, politiikan, tutkimuksen ja taiteen kentillä jo vakiinnuttaneet toimijat. J/S:n terrorismianalyysi osoittaa kauniisti ja kansantajuisesti syytösten katteettomuuden.

Markku Lahtelan Hallitsijan analyysissa kehitellään näennäishumanistin ja kauppapoliitikon käsitteet. Edellinen jakaa moraalisia tuomioita kaikille maailmassa tapahtuville vääryyksille samaan aikaan kun hänen koko elämänmuotonsa perustuu juuri noille samoille vääryyksille (saastuminen, Pohjoisen ja Etelän kuilu, kannattava asetuotanto jne.). Jälkimmäinen on realisti: hän näkee vääryydet ja pitää niitä hyvinvoinnin kulujen yhtenä osana.

Näiden ylitykseksi tarjotaan Deleuzen \& Guattarin voimalla skitsohumanismia:

\begin{abstract}
"Niin kauan kuin lukija jommalla kummalla tavalla etsii yhtä ja samaa ja ainoaa ja oikeaa tulkintaa hän on osa tuhoisaa ja ikävystyttävää idea-aggressiokonetta eikä kykene asettumaan tekstin maailman yläpuolelle, sanoutumaan irti omasta osuudestaan vallankäytön sairaassa mekaniikassa. Vain skitson ja zenmestarin hallitsema 'repeäminen' tarjoaa ulospääsyn." (J/S s. 117.)
\end{abstract}

Lahtelan teksti tulkitaan juuri skitsohumanismiin kutsuvaksi. Se on "terapeuttisten koanien, mahdottomien kysymysten sarja, yritys saada lukija virtaamaan tekstin mukana" (ibid.).

Tämä on lukemisen strategia, entä tekeminen (tarkkaan ottaen nämä eivät tietysti eroa toisistaan J/S:n konseptiossa)? Sehän vasta voi olla - näin olen kuullut sanottavan - poliittista. No terrorismi ainakin on tekemistä, siispä J/S suosittelee sitä.

Kuvion koukkuna on se, että me elämme jo alituisen terrorin alaisina. Kumpi on terroristi, sellaisen tehtaan toimitusjohtaja, joka huolekkaasti kirjanpitonsa osana maksaa kaikki yrityksensä saastepäästöistä koituvat sakot, vaiko näistä saatepäästöistä syövän saanut lähiseudun asukas, joka tilejä tasatakseen ampuu toimitusjohtajan? Entä onko todella niin itsestäänselvästi tuomittavaa osana poliittista taistelua merkitä tietyt yhteiskunnalliset positiot kuoleman merkillä ja systemaattisesti pyrkiä tuhoamaan esimerkiksi kaikki, jotka suostuvat asettumaan ydinvoimaloiden johtoon? Onnistuessaan käynnistämään yhteiskunnallisen prosessin tällaiset tapahtumakulut kai tuottavat kehityskulun, jonka tuloksia myöhemmin kerran vuodessa juhlitaan itsenäisyyspäivän tai vallankumouksen vuosipäivän merkeissä. Silloin niissä ei muistaakseni nähdä mitään tuomittavaa.

J/S:n mukaan on yhteiskunnallisten prosessien käynnistämiseen tähtäävän terrorismin aika kuitenkin jo ohi. Tällaisella terrorismilla ei enää nykyisen kaltaisessa totaalisessa koneistossa ole mahdollisuuksia, ja vaikka sillä olisikin mahdollisuuksia, se tuottaisi vain tuloksekseen yhtä terroristisen, vaikkakin hiukkasen toisenlaisen, koneiston kuin se, jonka kumoamiseen se alunperin pyrki. Valta tuottaa vastaliikkeessään käänteiskuvansa.

Siksi terrorismin avantgarde suuntautuu kohti terrorismin esteettisesti jalostettuja muotoja. Niiden motivaationa ei enää ole vaikuttaa suurten koneistojen toimintaan vaan mahdollistaa terroristille tuhonsa hetken, paikan ja tavan valinta ennen kuin suuret terrorikoneistot tekevät sen hänen puolestaan. Samalla esteettinen terrorismi voi toimia merkityspelinä ja (vaarallisena) leikkimisenä suurten terrorikoneistojen kanssa.

Vau miten rajua! Olinkin jo kyllästynyt tulitikkuihin! huudahtaa joku nuorempi establishmentfilosofi. Varsinaisesti J/S:n tarkoituksena ei kai (tai mistä minä sen voin tietää) olekaan niinkään suositella terrorismia reaalisena valintana jollekulle kuin osoittaa, että terrorismin vastustaminen yleensä on joko kauppapoliittista tai näennäishumanistista.

Mitä siis jää käteen? Eipä tietysti juuri muuta kuin Marcusen Suuri
Kieltäytyminen, mutta joskus siinäkin voi olla enemmän voimaa kuin toiminnassa vakiintuneiden retoristen kehysten puitteissa. Vai äänestitkö sinä presidentinvaaleissa? Entä oliko äänestämättä jättäminen mielestäsi "protesti"?

\section{Herjakirjoitusten puolesta}

$\mathrm{J} / \mathrm{S}: \mathrm{n}$ kieli on siivotonta. Se on siivottoman hyvää ja siivottoman herjaavaa. Lisäksi se on hävytöntä luodessaan retorisen asetelman, jossa jokin täysin uusi on ensimmäistä kertaa tunkeutumassa Suomeen ja joutuu siksi agonisesti asettumaan kaikkea ja kaikkia vastaan. Tämähän ei tietysti ole totta. Näin yksin eivät Eskelinen ja Lehtola ole. Kirjan julkaisee WSOY, Suomen suurin kustannustalo. Eino Leinon seura kutsuu kirjoittajat jäsenikseen. Lehdet kirjoittavat suuria arvosteluja. Televisio ottaa "nuoret vihaiset miehet" kuolaten syliinsä (edellisistä nuorista vihaisista onkin jo ennättänyt kulua monta kuukautta). Kansainvälisen kirjallisuuskritiikin kentillä on grand middle-aged man Jonathan Culler jo ehtinyt näyttää kuinka J/S:n tyyppisten kirjojen lähteitä voidaan lukea uuden, tekstuaalisuuden ongelmiin keskittyneen, kirjallisuuskritiikin perustan luovina Klassikoina. Suomessa ovat useiden eri yliopistojen eri laitoksilla varttuneet opiskelijat, assistentit ja tuntiopettajat (siis huomispäivän professorit) jo pitkään työskennelleet $\mathrm{J} / \mathrm{S}: \mathrm{n}$ lähteinä olevien tekstien parissa.

Mutta entä sitten? Sovellettu "jos et ole puolellamme, olet niiden puolella" retorinen strategia on yksi mahdollinen keskustelun käynnistämiseksi keskusteluhaluttomalla kentällä ja tällainen keskustelu on tietysti mahdollista vain, jos Eskelisen ja Lehtolan hengenheimolaiset jo ovat kaivautuneet asemiin yliopistojen laitosten vähäarvoisempiin positioihin. Se turvaa vähintään sen, ettei vallitseva kenttä ainakaan täysin ilman meteliä voi yksinkertaisesti sulkea hallussaan olevia rahoituslähteitä ja statusjärjestelmiä tulokkailta ja heidän asemissa odottavilta kumppaneiltaan.

Herjauskirjoitus puolestaan on Suomen kokoisessa maassa, jossa 


\section{TOTEUTUMATON VALTIOKAAPPAUS - KOHUTUN VÄITÖSKIRJAN EPÄARVOSTELU}

kaikki kentät niin helposti alkavat kiertää yhtä keskusta, aina paikallaan, jos se vain on henkevästi laadittu. On kaunista, että Markku Eskelinen ja Jyrki Lehtola ovat kirjoittaneet erinomaisen, huonoa makua osoittavan kirjan. Sitä tarvittiin.

Tämäkin arvostelu on kenttäkamppailua.

Risto Heiskala

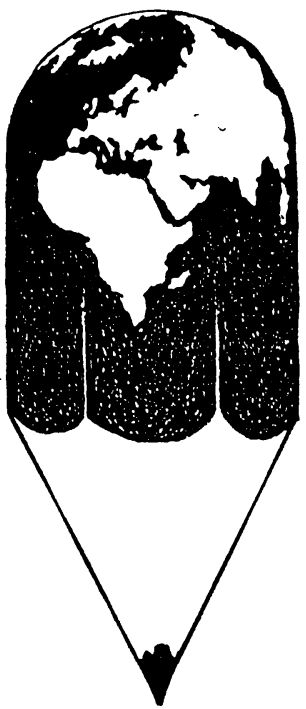

VUODEN 1988 YDINASIAT

Ydin-lehdestä vain tilaamalla

8 numeroa vain $90 \mathrm{mk}$

YDIN-lehti Veturitori $00520 \mathrm{HKI}$

p.90-144 991 ps-tili 1509 92-4
AHTI, MARTTI: Salaliiton ääriviivat. Oikeistoradikalismi ja hyökkää$v a ̈$ idänpolitiikka 1918-1919. Espoo: Weilin+Göös, 1987.

Martti Ahdin väitöskirja ei jätä kommentoijalleen paljon liikkumarakoa. Esittelyä "Salaliiton ääriviivat" ei totisesti enää kaipaa, siitä pitivät joka kotiin yltävät tiedotusvälineet tehokkaasti huolta, osin jo ennen väitöstä. Toisaalta tällaisesta aiheesta tällaiseen tapaan laadittu tutkimus on hyvin suojassa kritiikiltä: kun tekijän logiikka ei lipsu, asiasisältöön puuttuminen edellyttää kaiken käytetyn lähdemateriaalin tarkistamista ja/tai uuden löytämistä. Toinen vastaväittäjistä esitti ainakin yhden kiusalliselta kuulostaneen huomautuksen käyttämättä jääneestä tärkeästä lähteestä, mikä ei kuitenkaan näyttänyt väittelijää hermostuttavan.

Väitöskirja tarkastettiin kahden miehen voimin ja havaittiin kiitosten arvoiseksi, joten voin huoletta luottaa Martti Ahdin kertoneen aktivistien ja Mannerheimin salaliitosta kesällä 1919 tapahtumien osalta totuuden, koko tavoitettavissa olevan totuuden ja vain totuuden. Todettakoon varmuuden vuoksi, että suoritus ansaitsee minunkin mielestäni kaiken saamansa huomion. Myyttien kaataminen - etenkin suurmiesten suistaminen jalustoiltaan - ja toteutumattomien vaihtoehtojen kartoittaminen on Suomen kaltaisessa umpimielisessä maassa, jossa vääristellyillä historiakuvilla yhä edelleen on poikkeuksellisen kiihkeä kysyntä, historiantutkijan ehdoton - vaan ei ainoa - velvollisuus, jonka Martti Ahti on ansiokkaasti täyttänyt.

Väitöstilaisuudessa Ahti oli perin harvasanainen puolustaessaan tutkimustuloksiaan, vielä vähemmän hänellä oli intoa keskustella teoksensa muodosta. Tutkimuksesta kuulemma puuttuu yhteenveto, koska esitys on rakenteeltaan kertomus, jommoiset eivät yhteenvetoja kaipaa. Tämä kertomus ei todella kaipaakaan: on lukijan oma häpeä, jos hän ei saa selkeästi piirretystä jännittävästä tapahtumaketjusta ydinkohtia jäämään päähänsä. Kuten kaikki tietävät, Ahti päättää esityksensä poliittisten pienoiselämä- kertojen sikermään, jonka monimuotoisista, osin ristiriitaisista palasista rakentuu ällistyttävän selkeä kokonaiskuva suomalaisen oikeistoradikalismin aatehistoriasta. Ainakin minulle tämä kolmas pääluku edustaa teoksen arvokkainta antia ja osoittaa tekijän jo vuosia ennen väittelyä legendaariseksi tulleen perinpohjaisuuden koskevan myös niin sanottuja suuria linjoja eikä vain tapahtumahistoriallisia detaljeja.

Vaan kun minusta kolmas pääluku ei oikein kuulu samaan tarinaan kahden ensimmäisen kanssa. Aktivismin aatehistorian Ahti käy läpi alusta lähtien mutta tyytyy tapahtumahistoriallisessa osuudessa siihen palaan liikkeen tarinaa, jota ei vielä ollut kelvollisesti tutkittu. Työnekonomiset syyt, niinhän sitä aina sanotaan, mutta elämäkertoja rakentaessaan kirjoittaja ei selvästikään ole säästellyt vaivojaan sen paremmin materiaalin kuin selitystenkään etsinnässä. Kyseessä on siis mielestäni varsin kummallinen kertomus. Yllättäen Ahti ei väitöstilaisuudessa suostunut selvittämään, mitä hän tarkoittaa kertomuksella tieteellisen tutkimuksen muotona ja miksi hän oli väitöskirjatyössään sellaiseen päätynyt.

Vuorikadulla viihtyvät nuorisomuodin lisäksi myös intellektuaaliset muodit. Viime vuosina Historian tutkimus- ja dokumentaatiolaitoksen nuoret tutkijat ovat innostuneesti puhuneet narraatioista ja luovuttaneet selittämisen ja kokonaisyhteiskunnallisuuden kadun toisella puolella majailevien oikeushistorioitsijain harrastuksiksi. Ymmärtääkseni moista puhetta kaivan esiin Vuorikadulla kovasti kunnioitetun Matti Viikarin artikkelin "Samaa aihetta koskevien vaihtoehtoisten historiallisten kertomusten valintakriteereistä" (Historiallinen Arkisto 82. Vammala 1984). Toivottavasti tämä neljä vuotta vanha teksti katsotaan vielä ajantasaiseksi. Ensiksi opin, ettei historiallisen narraation ongelma ole lähimainkaan yksiulotteinen. Asettamalla tavoitteekseen mahdollisimman hyvien historiallisten kertomusten kirjoittamisen tutkija ei vielä saa käyttöönsä minkään koulukunnan valmista tutkimusotetta vaan hänen on vielä 